\title{
Changes in the volatile profile of skim milk powder prepared under different processing conditions and the effect on the volatile flavor profile of model white chocolate
}

\author{
Ashleigh Stewart, ${ }^{*}$ Alistair Grandison, ${ }^{*}$ Colette Fagan, ${ }^{*}$ Angela Ryan, $\dagger$ Daniel Festring, $\dagger$ and Jane K. Parker ${ }^{* 1}$ \\ *Department of Food and Nutritional Sciences, University of Reading, Reading RG6 6AP, United Kingdom \\ †Nestlé Product Technology Centre Confectionery, PO Box 204, Haxby Road, York YO91 1XY, United Kingdom
}

\begin{abstract}
The objective of this work is to determine the extent to which changes in the skim milk powder (SMP) manufacturing process alter the volatile profile of SMP, and whether these changes are carried through to a final product when the SMP is used as an ingredient and subjected to further processing. The manufacture of SMP is a multistage process involving a preliminary concentration step, heat treatment, and a drying stage. However, the methods and conditions used by the industry are not standardized, and the inherent variability in the production of SMP has consequences for the end-users, such as the confectionery industry, where the SMP is used as an ingredient during the production of milk chocolate, white chocolate, and caramel. This study investigates the effect of each stage of the manufacturing process on the concentration of reducing sugars and available amino groups (as precursors of the Maillard reaction) as well as on the volatile products of the Maillard reaction and lipid degradation. Eight types of SMP were produced using combinations of different processing conditions: concentration (by evaporation or reverse osmosis), heat treatment (low heat or high heat), and drying (spray-drying or freeze-drying). Maillard precursors were quantified after each processing stage and volatile compounds were extracted using solid-phase microextraction, and analyzed by gas chromatography-mass spectrometry. The resulting SMP were incorporated into a model white chocolate system, produced under varying conching conditions. We demonstrate not only that changes in the SMP manufacturing conditions affect the volatile profile of SMP, but also that these differences can be carried through to a final product when the SMP is used to
\end{abstract}

Received January 8, 2018.

Accepted June 26, 2018.

${ }^{1}$ Corresponding author: j.k.parker@reading.ac.uk prepare a model white chocolate. Understanding these differences is important to the industry for controlling the flavor of the end product.

Key words: manufacture of skim milk powder, flavor, spray dry, freeze dry, chocolate

\section{INTRODUCTION}

The manufacture of skim milk powder (SMP) is a multistage process involving a preliminary concentration step; heat treatment, which is often included to control the functional properties of the final powder (Oldfield et al., 2005); and a drying stage. Because these all involve a rise in temperature, lipid degradation and the Maillard reaction can occur during any of these steps. The severity of the heat treatment applied to milk during milk powder production is classified by industry according to the levels of undenatured whey proteins present (i.e., whey protein nitrogen index). High heat powder, medium heat powder, and low heat powder have whey protein nitrogen index ranges of $<1.5,1.5-6.0$, and $>6.0 \mathrm{mg} / \mathrm{g}$, respectively, and these can be achieved using a range of different time temperature combinations. Low-heat SMP is typically treated at $75^{\circ} \mathrm{C}$ for $20 \mathrm{~s}$, whereas medium heat conditions range from 85 to $105^{\circ} \mathrm{C}$ for 1 to $2 \mathrm{~min}$, and high heat up to $135^{\circ} \mathrm{C}$ for 2 to $3 \mathrm{~min}$ (Early, 1998). Given this range of conditions, the extent of the Maillard reaction in SMP is variable. An understanding of the critical control points during the manufacturing process is important to industries that require a consistent product.

The changes in milk powder during storage are well documented (Hurrell et al., 1983; Driscoll et al., 1985; Karagül-Yüceer et al., 2002, 2003; Drake et al., 2006). Most studies show that the formation of lipid-derived volatiles is prevalent during storage, contributing to the development of off-notes, but both formation and loss of Maillard reaction products were reported, depending on the conditions.

Research on high-temperature processes in milk tends to focus on UHT (Morales et al., 1992; Celestino 
et al., 1997; Romero et al., 2001; Valero et al., 2001; Tokuşoğlu et al., 2004) and sterilization (Contarini et al., 1997). The formation of Maillard intermediates and glycation products during manufacture of dairy products has been studied (Birlouez-Aragon et al., 2004; Erbersdobler and Somoza, 2007; Cattaneo et al., 2008), but the focus of these studies was the reduction in nutritional value as a result of lysine residues becoming unavailable (Mehta and Deeth, 2016). The development of volatile aroma compounds during the production of milk powder was studied by Drake et al. (2006) who showed that Maillard-derived compounds such as 2-acetylpyrrole, 2-acetylthiazole, and 2-acetyl2-thiazoline increased, whereas little change occurred in the profile of the lipid degradation products. However, Li et al. (2012) monitored volatile lipid oxidation compounds during the production of milk powder, and demonstrated that all stages of the process could influence the formation and stability of these volatiles.

Recently, the role in flavor formation of the individual unit operations have been investigated. Falling-film evaporators are used extensively in the dairy industry, and evaporation (EV) under vacuum results in the milk being heated to a lower temperature. Other concentration methods include membrane separation techniques such as reverse osmosis (RO; Glover, 1985), which operates at high pressure and temperatures below those reached during EV. Comparison of RO, nanofiltration, and UF was discussed by Syrios et al. (2011) with regard to stability, pH, calcium content, and gel formation. Park and Drake (2016) showed that concentration by $\mathrm{RO}$, compared with concentration by $\mathrm{EV}$, retained far more of the sweet character of the milk, driven by a greater retention of most volatiles, particularly lactones and furaneol. Maltol, however, showed the reverse trend. Park et al. (2016) also showed significant changes in the volatile profile when different spray-drying parameters were employed. They showed that the sweet aromatic note increased as the inlet temperature increased, and this correlated with an increase in some lactones, maltol, and vanillin.

Given the significant changes in SMP brought about by different processing conditions, it is important to understand if these changes are reflected in the final products when SMP is used as an ingredient for the manufacture of more complex food products. Caudle et al. (2005) showed a decrease in consumer acceptability of SMP as the storage time increased up to 4 yr, and when these SMP were incorporated into ice cream, yogurt, and white chocolate (but not hot chocolate), a similar decrease in consumer acceptability was observed. Volatile analysis of the SMP showed an increase in dimethyl sulfide and dimethyl disulfide, and a decrease in maltol. Lloyd et el. (2009b) carried out a similar experiment with stored WMP incorporated in white and milk chocolate and showed a similar decrease in consumer acceptance, which was attributed to an increase in lipid degradation products. Recently, Stewart et al. (2017) showed that the heat treatment applied during SMP manufacture leads to both changes in the aroma profile of the SMP, and flavor changes in white chocolate prepared from the resulting SMP.

The aim of this work was to investigate different processing conditions during the production of SMP to determine the key stages for flavor development, and to determine whether these changes are carried through to a final product. Eight types of skim milk powders were produced using combinations of different processing conditions. Maillard precursors (sugars and AA) and aroma compounds were quantified after each stage. The SMP were incorporated into a model white chocolate system and heated to mimic conching to determine the effect of milk processing methods on the flavor profile of a final confectionery product.

\section{MATERIALS AND METHODS}

\section{Chemicals}

Trehalose, glucose, galactose, lactose and lactulose, L-leucine, sodium hydroxide $(50 \%$ solution in water; $1.515 \mathrm{~g} / \mathrm{mL})$, SDS, ethanol, o-phthaldialdehyde (OPA), 2-mercaptoethanol, sodium tetraborate buffer solution ( $\mathrm{pH}$ 9), 1,2-dichlorobenzene, methanol, all aroma chemical, alkanes $\mathrm{C}_{5}-\mathrm{C}_{30}$, and diethyl ether were obtained from Sigma-Aldrich Co. (Dorset, UK). The EZ:Faast amino acid analysis kit was purchased from Phenomenex (Macclesfield, UK).

\section{Preparation of Milk Powders}

Raw whole bovine milk $\left(\mathbf{R W M}_{\mathbf{R O}} ; 40 \mathrm{~kg}\right)$ supplied by The University of Reading CEDAR Dairy Farm (CEDAR, Reading, UK) was pasteurized at $72^{\circ} \mathrm{C}$ for $15 \mathrm{~s}$ and separated using a disc bowl centrifuge. The skimmed pasteurized milk $\left(\mathbf{P M}_{\mathbf{R O}}\right)$ was then concentrated to $20 \%$ TS using RO to produce concentrated milk $\left(\mathbf{C M}_{\mathbf{R O}}\right)$. Half of the concentrated milk was then subjected to a heat treatment stage to give a heated concentrated milk $\left(\mathbf{H C M}_{\mathbf{R O}}\right)$, and no heat treatment was applied to the other half. The concentrated milks were then spray-dried (SD) or freeze-dried (FD) to produce the following milk powders: $\mathrm{SDMP}_{\mathrm{RO}}$, HSD-

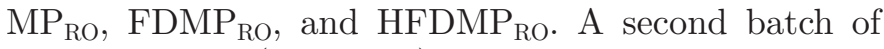
raw whole milk $\left(\mathbf{R W} \mathbf{M}_{\mathbf{E V}}\right)$ was obtained one week later from the same herd, and the process was repeated concentrating to $20 \%$ solids using EV to produce a second set of milks $\left(\mathrm{RWM}_{\mathrm{EV}}, \mathrm{PM}_{\mathrm{EV}}, \mathrm{CM}_{\mathrm{EV}}\right.$, and $\left.\mathrm{HCM}_{\mathrm{EV}}\right)$ and 
milk powders $\left(\mathrm{SDMP}_{\mathrm{EV}}, \mathrm{HSDMP}_{\mathrm{EV}}, \mathrm{FDMP}_{\mathrm{EV}}\right.$, and $\left.\mathrm{HFDMP}_{\mathrm{EV}}\right)$.

Reverse Osmosis. Reverse osmosis was carried out at $6 \mathrm{MPa}$ outlet pressure using the RO module described previously by Syrios et al. (2011) until the TS content was 20\%, assessed using a Lactoscope (Quadrachem Laboratories Ltd., London, UK). Changes in the protein, fat, lactose, and TS content were previously measured throughout the process (Stewart et al., 2017). The temperature of concentrated milk during $\mathrm{RO}$ was $30^{\circ} \mathrm{C}$.

Evaporation. Evaporation was carried out using a single-stage rising film evaporator (pressure $=180 \mathrm{kPa}$ ) until a concentration of $20 \%$ TS was achieved. Milk was concentrated in 10-kg batches and the temperature of the milk during $\mathrm{EV}$ was 54 to $55^{\circ} \mathrm{C}$.

Heat Treatment. Half the concentrated milk was subjected to an additional heat treatment of $5 \mathrm{~min}$ at $125^{\circ} \mathrm{C}$, achieved by transferring milk to Duran bottles $(80 \mathrm{~mL})$ and heating batches of 7 bottles in an autoclave (CertoClav Sterilizer, Traun, Austria). No additional heat treatment was applied to the second half of the concentrated milk.

Spray-Drying. Spray-drying was carried out using a NIRO spray dryer (Copenhagen, Denmark) with an A/S NIRO atomizer. The inlet air temperature was fixed at $200^{\circ} \mathrm{C}$ and the feed flow rate adjusted to give an outlet air temperature of 80 to $90^{\circ} \mathrm{C}$. The wet bulb temperature during spray-drying was 45 to $50^{\circ} \mathrm{C}$.

Freeze-Drying. Prior to freeze-drying, the milk was frozen at $-80^{\circ} \mathrm{C}$ for $24 \mathrm{~h}$. Freeze-drying was carried out using a Christ Gamma 2-16 LSC freeze-dryer (120 h, pressure $<10 \mathrm{kPa}$; Martin Christ, Osterode, Germany).

\section{Preparation of Model White Chocolate}

White chocolate was prepared as described by Stewart et al. (2017). The conching process of white chocolate was mimicked using a 250-mL continuously stirred reactor vessel (Atlas Potassium, Syrris Inc., Royston, UK) under different heating conditions. A preliminary study was carried out to test different conching conditions, heating the model white chocolate (produced with commercial SMP) at 4 temperature/ time combinations: $4 \mathrm{~h}$ at $50^{\circ} \mathrm{C}, 4 \mathrm{~h}$ at $80^{\circ} \mathrm{C}, 8 \mathrm{~h}$ at $50^{\circ} \mathrm{C}$, and $8 \mathrm{~h}$ at $80^{\circ} \mathrm{C}$. The 2 extremes were chosen for a comparison to identify potential differences as a result of conching time and temperature. For each milk powder, 2 model white chocolates were produced using either mild conching conditions $\left(4 \mathrm{~h}\right.$ at $\left.50^{\circ} \mathrm{C}\right)$ or harsh conditions $\left(8 \mathrm{~h}\right.$ at $\left.80^{\circ} \mathrm{C}\right)$. Model white chocolate was refrigerated and stored at $4 \pm 1^{\circ} \mathrm{C}$ before analysis. A control white chocolate was also produced containing all ingredients apart from SMP, to confirm that dif- ferences observed were as a result of the SMP and not due to other ingredients. This control was conched for $8 \mathrm{~h}$ at $80^{\circ} \mathrm{C}$ and analyzed under the same conditions as other samples.

\section{Analytical Methods}

Prior to analysis, all milk samples were diluted to $8 \%$ solids in water and powder samples were reconstituted in water to $8 \%$ TS.

Determination of Sugars by Ion Chromatography. An aliquot $(400 \mu \mathrm{L})$ of each sample was transferred to an Amicon $0.5 \mathrm{~mL}$ of $3 \mathrm{kDa}$ MWCO filter (Millipore, Watford, UK) and centrifuged for $20 \mathrm{~min}$ at $12,000 \times g$ at room temperature. The filtrate was diluted 200 -fold in water and $500 \mu \mathrm{L}$ of this diluted sample was combined with $500 \mu \mathrm{L}$ of a $40 \mathrm{~g} / \mathrm{L}$ of trehalose solution. Extracts were analyzed using a Dionex ion chromatography system (Dionex Corp., Sunnyvale, CA), which consisted of an AS50 autosampler, LC25 column oven, GS50 pumps, and an ED50 pulsed amperometric detector, running in internal amperometric mode. Separation was carried out on a Carbopac PA1 column (Dionex Corp.; $250 \times 4 \mathrm{~mm}$ i.d.) coupled with a guard column $(50 \mathrm{~mm} \times 4 \mathrm{~mm}$ i.d.), using an injection volume of $20 \mu \mathrm{L}$. A gradient program was set up using water and $200 \mathrm{mM} \mathrm{NaOH}$ at a flow rate of $1 \mathrm{~mL} /$ min as follows: $40 \mathrm{~min}$ at $12 \mathrm{mM} \mathrm{NaOH}, 5 \mathrm{~min}$ at 200 $\mathrm{m} M \mathrm{NaOH}$, and finally re-equilibrated for $5 \mathrm{~min}$ at 12 $\mathrm{m} M \mathrm{NaOH}$. The waveform of the pulsed amperometric detector was as follows: $400 \mathrm{~ms}$ at $0.1 \mathrm{~V}, 20 \mathrm{~ms}$ at -2.0 $\mathrm{V}, 10 \mathrm{~ms}$ at $0.6 \mathrm{~V}$, and $60 \mathrm{~ms}$ at $-0.15 \mathrm{~V}$. Standards of glucose, galactose, lactose, and lactulose were used to produce a series of calibration curves, using trehalose as an internal standard, for quantification. Chromeleon software was used to operate the system, as well as for data quantification. All samples were analyzed in triplicate.

Determination of Total Available Amino Groups. Aqueous samples were diluted 5-fold in water, followed by derivatization using OPA and spectrophotometric analysis as described previously by Brands and Van Boekel (2001). A calibration curve was obtained from L-leucine, which had been derivatized using the same method. All samples were analyzed in triplicate.

Determination of Free Amino Acids by GC$M S$. An aliquot of each aqueous sample $(100 \mu \mathrm{L})$ was derivatized using the EZ:Faast free amino acid analysis kit for GC-MS (Phenomenex, Macclesfield, UK). The GC-MS analysis was carried out as described previously by Elmore et al. (2007).

Measurement of Moisture Content and Water Activity. Moisture content of the skim milk powders was determined by Karl Fischer titration using an Orion 
AF8 volumetric Karl Fischer unit (Thermo Scientific, Waltham, MA). Milk powder samples $(0.2 \mathrm{~g})$ were analyzed at room temperature using CombiTitrant 5 (Merck, Darmstadt, Germany) as the titrating agent and methanol as the solvent. The solvent was changed at every replicate and analyses were performed at least in duplicate to give less than $0.08 \%$ difference between readings, which were averaged. The water activity $\left(\mathbf{a}_{\mathbf{w}}\right)$ of milk powder samples $(0.5 \mathrm{~g})$ was measured at $25^{\circ} \mathrm{C}$ using a LabMaster- $\mathrm{a}_{\mathrm{w}}$ (Novasina, Lachen, Switzerland).

Microscopy. A small amount of each powder was applied to a microscope slide and observed using a stereoscopic microscope (SZ 60, Olympus, Tokyo, Japan) equipped with lighting (Highlight 3000, Olympus, Southend-on-Sea, UK). Photographic images of each sample were acquired with a digital camera and data capture software (VisiCam 5.0, VWR, Oud-Heverlee, Belgium).

Solid-Phase Microextraction/GC-MS. Volatile compounds were extracted from liquid milk, milk powder, and white chocolate samples using an automated solid-phase microextraction (SPME)/GC-MS system (Agilent, Santa Clara, CA), equipped with a DVB/ CAR/PDMS Stableflex fiber (Supelco, Bellefonte, PA). Samples $(4 \mathrm{~g})$ were weighed into $20-\mathrm{mL}$ glass SPME vials and analyzed using the method detailed previously by Stewart et al. (2015). An internal standard (10 $\mu \mathrm{L}$ of $130.6 \mu \mathrm{g} / \mathrm{mL}$ of 1,2 -dichlorobenzene in methanol) was added to aqueous samples. No internal standard was added to model white chocolate samples, but instrument sensitivity was checked by running a standard of 1,2-dichlorobenzene $(10 \mu \mathrm{L}, 130.6 \mu \mathrm{g} / \mathrm{mL}$ in methanol) at regular intervals. All samples were analyzed in triplicate.

\section{Statistical Analysis}

One-way ANOVA was carried out using XLSTAT Version 2012.4.02 (Addinsoft, Paris, France), and Tukey's honestly significant difference test was applied to determine which sample means differed significantly at $P=0.05$.

\section{RESULTS AND DISCUSSION}

\section{Milk Powder Manufacture}

The milk powders were prepared from milk supplied by the University of Reading CEDAR Dairy farm and processed using the equipment available at the University of Reading Food Processing Centre. This allowed us to control the origin and processing of the milk very closely, but, as such, we could not match the manufacturing conditions used in the industry. Although the processing conditions applied to the milk were selected to match industry heating profiles as closely as possible, the heat load on a smaller scale, may be different. A pilot scale can never be fully representative of a full-scale industrial process, but this paper provides the evidence required to move to industrial trials where validation of the results could take place.

\section{Maillard Precursors}

Eight different SMP were produced using a combination of techniques, which varied in the level of thermal processing applied. Reverse osmosis and EV were used to concentrate the milk, followed by spray-drying or freeze-drying. Half the milk was also subjected to a heat treatment of $5 \mathrm{~min}$ at $125^{\circ} \mathrm{C}$ between the concentration and drying stages. Precursors (sugars, free amino acids, and available amino groups) were quantified after each stage of processing to monitor progress of the Maillard reaction. Table 1 shows the differences in concentration of Maillard precursors throughout the processing of SMP.

It was necessary to use 2 different batches of RWM, one of which was concentrated by EV and the other by RO. However, the batches were produced $<7 \mathrm{~d}$ apart, and analysis of the raw milks and pasteurized milks $(\mathbf{P M})$ showed only minor differences. Batch 2 (EV) contained higher $(P<0.05)$ concentrations of sugars and free amino acids in comparison to the first batch (RO). We compared the general trends within the first batch (i.e., whether a relative increase or decrease occurred after each step) with the general trends in the second batch, but no quantitative conclusions could be made when directly comparing $\mathrm{EV}$ and RO samples.

Sugars. Lactose is the most abundant component in SMP, comprising approximately $50 \%$ of the dry weight (Martin et al., 2007), and is known to react at elevated temperatures with free amino groups via the Maillard reaction. Table 1 shows a loss of lactose during the concentration steps for both RO and EV batches of RWM (loss of 150 and $130 \mathrm{mmol}$ per $\mathrm{kg}$ of dry weight, respectively), and both galactose and glucose also showed losses. One potential route for loss of reducing sugars is via reaction with free amino groups to form a Schiff's base. However, the changes in the concentration of the free amino groups were insufficient to account for the loss of lactose, and no isomerization to lactulose was observed.

The effect of heat treatment was more apparent for lactulose, regardless of the concentration method used. Lactulose was present in samples only after the heat treatment stage and its concentration increased further after spray-drying. Lactulose is formed from the Lobry de Bruyn-Alberda van Ekenstein transformation of 
STEWART ET AL.

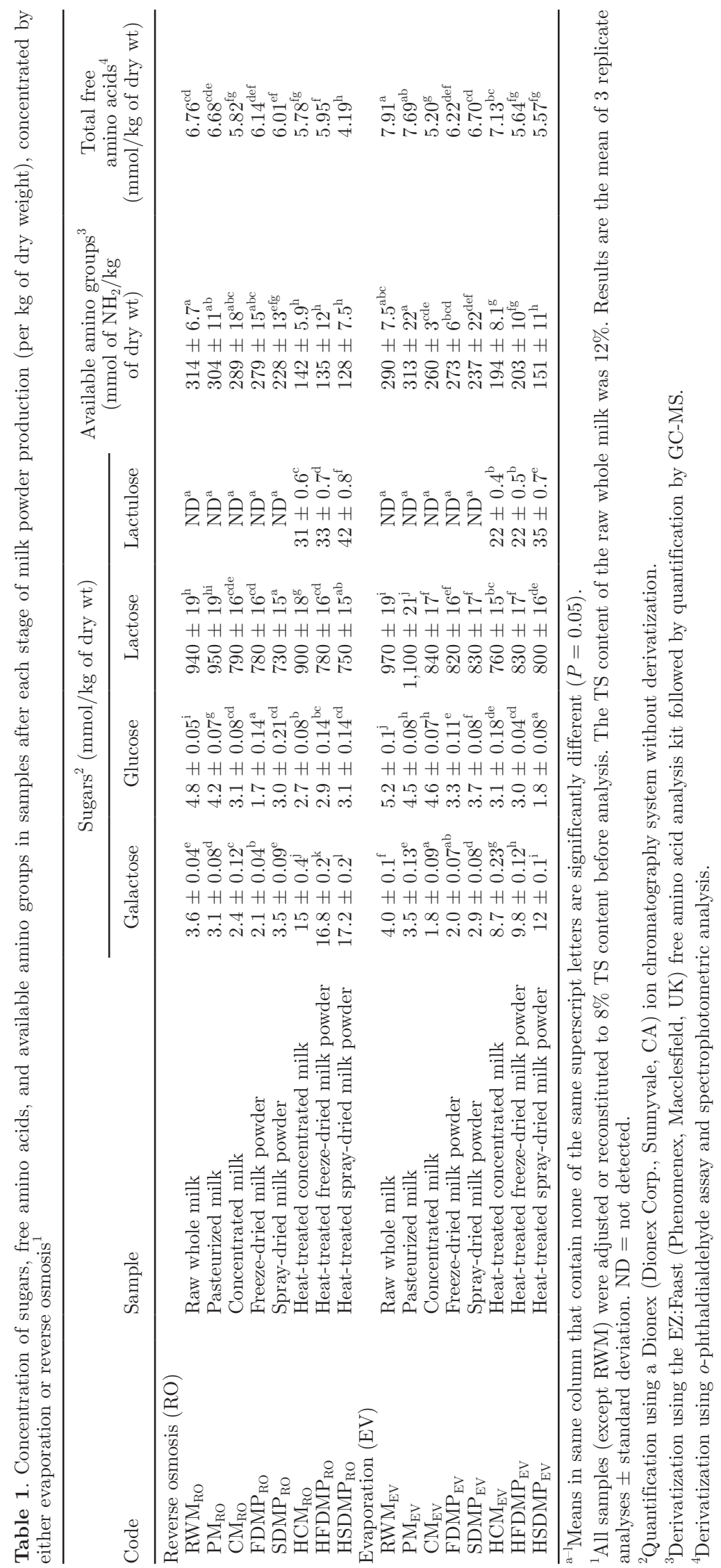


lactose during heating and has been used as a marker for heat treatment in milk (Marconi et al., 2004). Additionally, we noticed that lactulose was not formed after spray-drying alone, as it was not detected in either of the spray-dried milk powders (SDMP) with no heat treatment. This suggests it is the high temperature applied during heat treatment $\left(125^{\circ} \mathrm{C}\right)$ that induces the initial stages of lactose isomerization, which can then continue during further thermal processing (spray-drying) to form lactulose. These results support the previous use of lactulose as a marker of severity of SMP heat treatment. However, work by Berg and Van Boekel (1994) showed that degradation of lactulose to galactose, formic acid, and C5/6 compounds occurs after extended heating at high temperatures $\left(>140^{\circ} \mathrm{C}\right)$.

The monosaccharides glucose and galactose were both present at low concentrations in RWM. During processing, we observed an overall decrease in glucose of $30 \%$ or more from RWM to the finished milk powder for all combinations of processing. About $12 \%$ was lost during pasteurization (both for RO and EV batches) and further loss occurred during heat treatment, which was greater for $\mathrm{HCM}_{\mathrm{EV}}$ than $\mathrm{HCM}_{\mathrm{RO}}$ and for which we have no explanation. The loss of glucose during freezedrying of the unheated milk $(\mathrm{CM})$ is more than might be expected and is difficult to explain, whereas upon freeze-drying of the heated milk (HCM), no significant change occurs. We observed that the most significant decrease in glucose concentration was from $\mathrm{RWM}_{\mathrm{EV}}$ to $\mathrm{HSDMP}_{\mathrm{EV}}$, which represents the powder produced under the most severe combination of processing conditions.

We found that the loss of galactose during pasteurization (13\%; both RO and EV) was similar to that for glucose but, in contrast to glucose, we found a 5-fold increase in galactose concentration after heat treatment for both $\mathrm{HCM}_{\mathrm{EV}}$ and $\mathrm{HCM}_{\mathrm{RO}}$. During the Maillard reaction of lactose with an $\varepsilon$-amino group, the glucose moiety is the reducing sugar, which participates in the first stage of the Maillard reaction. It may remain bound to protein or further degrade to form volatile flavor compounds (Van Boekel, 1998) during which an intact galactose unit is cleaved off. This explains why galactose concentration increased after the heat treatment step, but no equivalent increase occurred for glucose. Consistent with this explanation, we also noticed small increases $(P<0.05)$ in galactose but not glucose when the concentrated milks were spray-dried, and this change in galactose was less or insignificant when the concentrated milks were freeze-dried. This is consistent with the higher temperatures reached in the spray-drying process compared with the freeze-drying.

Amino Groups. The OPA spectrophotometric assay used to quantify available amino groups gives an approximation of the total number of available amino groups (i.e., those not bound to sugars). The most significant loss we observed was for the high heat spray-dried powders, with $48 \%$ (139 mmol of $\mathrm{NH}_{2} / \mathrm{kg}$ ) lost from RWM $\mathrm{RV}_{\mathrm{EV}}$ to $\mathrm{HSDMP}_{\mathrm{EV}}$ and $59 \%$ (186 mmol of $\mathrm{NH}_{2} / \mathrm{kg}$ ) lost from $\mathrm{RWM}_{\mathrm{RO}}$ to $\mathrm{HSDMP}_{\mathrm{RO}}$. These overall losses are of a similar magnitude to the losses of lactose, which are 170 and $190 \mathrm{mmol}$, respectively. Lactose binds to amino groups during the Maillard reaction to form the Amadori rearrangement product (ARP), making these amino groups unavailable and not quantified by this technique. Therefore it makes sense that the concentration of available amino groups decreased with increased heating.

Little correlation was observed between the level of thermal processing and the total concentration of free amino acids. Although free amino acids are involved in the Maillard reaction at elevated temperatures, there may also be a small degree of proteolysis during processing, releasing free amino acids from the casein or whey protein. Free amino acids are also regenerated by the Maillard reaction during rearrangement of the Amadori rearrangement product to deoxyosones. This would explain the insignificant changes to the total free amino acid concentration.

Figure 1 shows variation in the concentration of lysine, which demonstrated a significant decrease in concentration during thermal processing. Lysine residues in milk proteins are considered to be the most important for the Maillard reaction in milk powder due to the free and highly reactive $\varepsilon$-amino group, but free lysine also has an additional $\alpha$-amino group (O'Brien, 2003) that can participate. This is supported by the results of this study, as free lysine concentration can be seen to decrease $(P<0.05)$ with increased heating, likely to be the result of the Maillard reaction with lactose. Lysine concentration decreased after concentration by both $\mathrm{RO}$ and $\mathrm{EV}$, and although only the decrease from $\mathrm{RO}$ was statistically significant, the trend was the same for EV. However, the decrease from PM to HCM was significant for both concentration methods.

Generally little difference was observed between batches concentrated by $\mathrm{EV}$ and $\mathrm{RO}$, compared with the bigger changes in Maillard precursors that took place during the heat treatment, and to a lesser extent during spray-drying.

\section{Physical Properties of Skim Milk Powders}

The moisture content and $\mathrm{a}_{\mathrm{w}}$ values measured for each powder are shown in Figure 2. It can be seen that FD powders consistently had higher moisture contents and $\mathrm{a}_{\mathrm{w}}$ compared with SD samples. With the exception of HSDMP concentrated by RO, heat-treated samples 


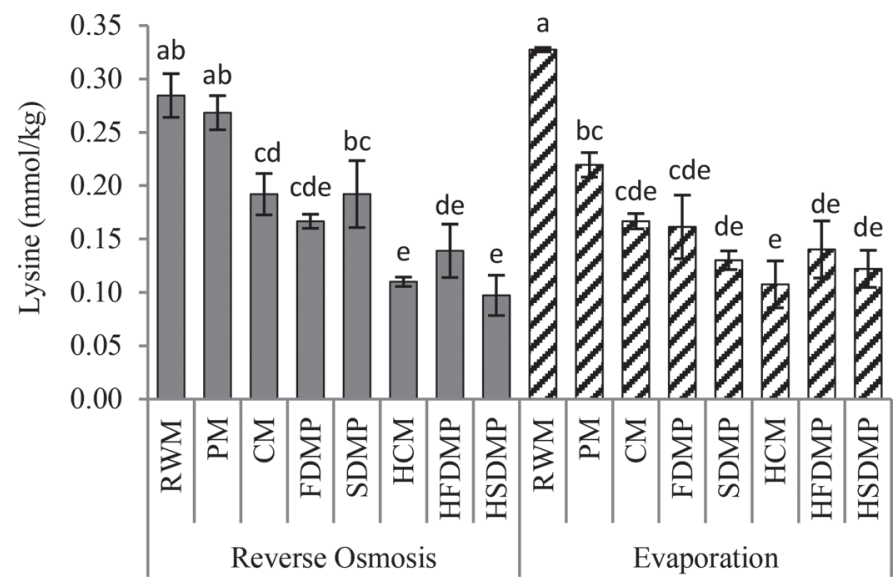

Figure 1. Variation in the concentration of lysine during processing of skim milk powder (SMP) using 2 different concentration methods: reverse osmosis and evaporation. $\mathrm{RWM}=$ raw milk; $\mathrm{PM}=$ pasteurized milk; $\mathrm{CM}=$ concentrated milk; $\mathrm{HCM}=$ heat-treated concentrated milk; SDMP = spray-dried milk powder; HSDMP = heattreated spray-dried milk powder; FDMP $=$ freeze-dried milk powder; HFDMP $=$ heat-treated freeze-dried milk powder. All samples were made up to $8 \%$ TS content before analysis. Results are the mean of 3 replicate analyses \pm standard deviation (error bars). Bars not labeled with the same letters are significantly different $(P=0.05)$.

had a slightly lower moisture content and $\mathrm{a}_{\mathrm{w}}$ than the corresponding unheated samples.

Commercial milk powders are produced with a moisture content of 2 to $4 \%$ (Smit, 2003) to prevent deterioration by bacterial growth or processes such as the Maillard reaction and lipid oxidation, which would also

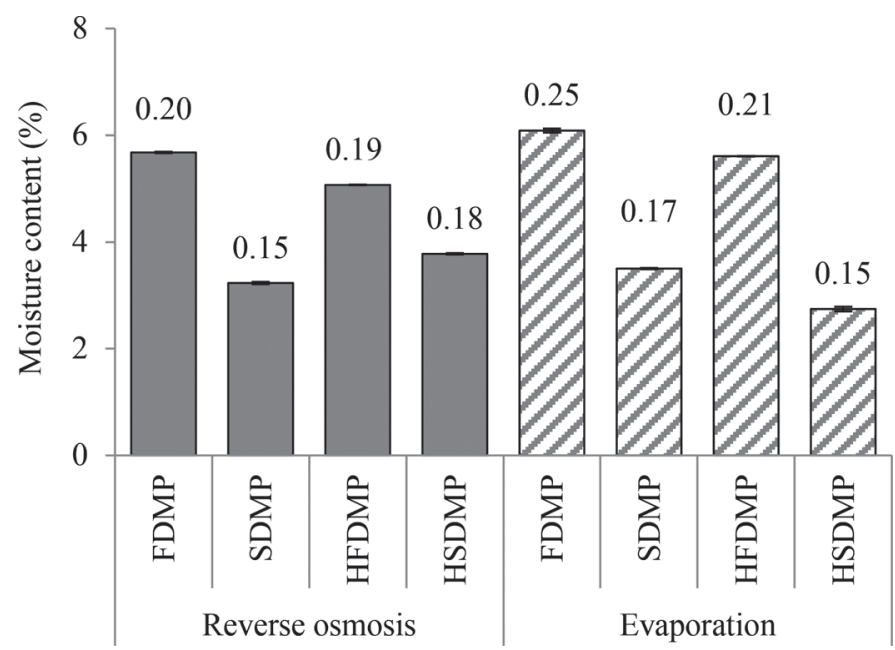

Figure 2. Moisture content (\%) of milk powder samples, determined by Karl Fischer titration. Means of duplicate analyses \pm standard deviation as error bars. The number above each bar denotes the water activity $\left(\mathrm{a}_{\mathrm{w}}\right)$. FDMP $=$ freeze-dried milk powder; SDMP $=$ spray-dried milk powder; HFDMP = heat-treated freeze-dried milk powder; HSDMP = heat-treated spray-dried milk powder. change the flavor profile of the product. Freeze-dried powders in this study had a moisture content of $\sim 5$ to $6 \%$, making them more susceptible to deterioration and subsequent flavor formation. The higher moisture content and $\mathrm{a}_{\mathrm{w}}$ had a significant effect on flavor formation after incorporation of the powders into a model white chocolate system, which is discussed below.

Substantial differences can be seen in the surface structure of the powders by microscopy (Figure 3), which agree with previous findings by Miao and Roos (2004). Whereas spray-dried samples were spherical with a smooth surface, freeze-dried powders were irregular in shape with a surface resembling broken glass. Despite clear differences in surface structure, lactose is highly likely to be in the amorphous state in both powders as water is removed faster than crystallization can occur during spray-drying, and lactose molecules are unable to move themselves into a crystalline arrangement in a frozen matrix before freeze-drying. Therefore, though the solid state of lactose is unlikely to be different as a result of the different drying methods, the particle size and shape may have influenced the rate of Maillard reaction taking place. In addition, the higher moisture content of the FDMP is more likely to allow reactants to come into contact with one another. The optimum moisture content for the Maillard reaction in SMP is $7 \%$ (Franzen et al., 1990) above which the system is diluted and reactants are less likely to come into contact. The FDMP are closer to this optimum moisture content, which is likely to enhance the Maillard reaction in those powders during further processing.

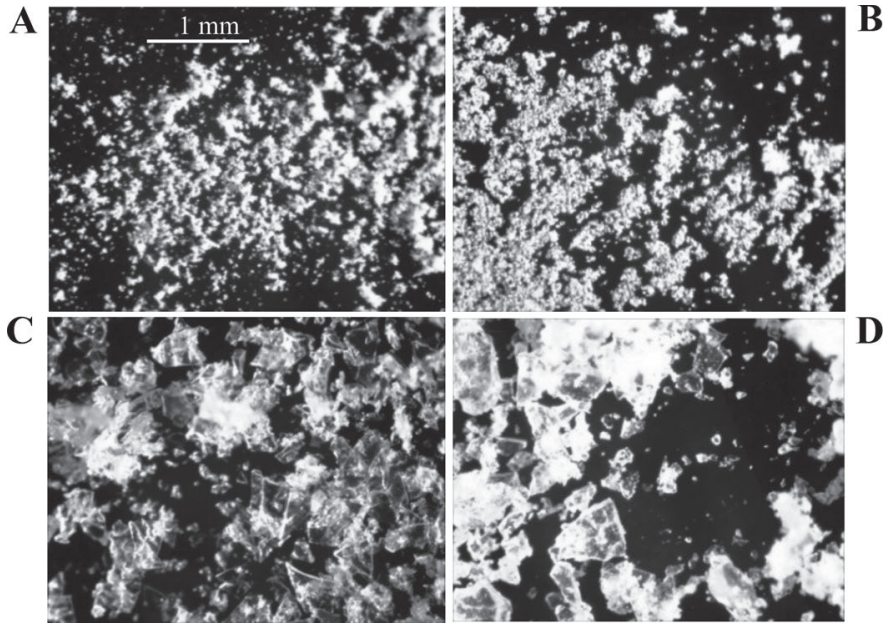

Figure 3. Optical micrographs of heated spray-dried milk powder (HSDMP) or freeze-dried milk powder (HFDMP) produced from milk concentrated by reverse osmosis (RO) or evaporation (EV). (A) $\mathrm{HSDMP}_{\mathrm{RO}},(\mathrm{B}) \mathrm{HSDMP}_{\mathrm{EV}},(\mathrm{C}) \mathrm{HFDMP}_{\mathrm{RO}}$, and (D) HFDMP $\mathrm{EV}_{\text {. }}$ 


\section{Volatile Compounds in Intermediate Milk Products (RWM, CM, PM, and HCM)}

The volatile compounds identified in samples by SPME/GC-MS are shown in Table 2 for raw, pasteurized, concentrated, and heat-treated samples. (The reconstituted milk powders are shown in Table 3 and discussed below).

Lipid-Derived Volatiles. Of the 22 volatile compounds identified, 11 were products of lipid oxidation, primarily straight-chain aldehydes (pentanal, hexanal, heptanal, octanal, nonanal, and decanal) and methyl ketones (2-heptanone, 2-nonanone, 2-decanone, and 2 -undecanone). These compounds have all been identified previously in heated milk (Vazquez-Landaverde et al., 2005) and SMP (Bassette and Keeney, 1960; Walker, 1972; Shimamura and Ukeda, 2012), although they are generally considered to contribute off-notes to SMP flavor. Autoxidation of lipids in milk is catalyzed by both light and heat and therefore any processing stage that applies heat and exposes the milk to light would be expected to increase the concentration of lipid oxidation products.

Interestingly, only 2 of these were identified in the volatile profile of RWM, whereas 9 were identified in the PM. This could be due to the different flavor release properties of the RWM, which contains $4 \%$ fat compared with the other samples, which had a fat content of $<0.1$. The higher fat content can decrease the partitioning of the lipophilic aldehydes and ketones into the headspace. It could also be due to the (relatively mild) processing conditions applied during pasteurization (15 $\mathrm{s}$ at $72^{\circ} \mathrm{C}$ ) initiating the oxidative process. VazquezLandaverde et al. (2005) compared by SPME/GC-MS the volatile profile of commercial PM at $0,1,2$, and $3 \%$ fat content, and found no consistent or significant decrease in the concentration of these volatiles in the headspace as the fat content increased, suggesting that the lack of these compounds in the headspace of RWM is not due to differences in the flavor release. However, they also reported the presence of these compounds in the raw milk as well as the pasteurized samples, with few significant differences between them, suggesting that they are not formed during pasteurization. However, these observation were made in commercial samples, whereas ours have all been prepared from the same 2 batches of raw milk.

During the subsequent concentration, comparison of $\mathrm{RO}$ and $\mathrm{EV}$ showed that $\mathrm{CM}_{\mathrm{RO}}$ contained more aldehydes (particularly hexanal) and acids compared with $\mathrm{CM}_{\mathrm{EV}}$, although the differences were not always significant. This is consistent with Park and Drake (2016) who showed that RO retained in general more aldehydes, lactones, and acids. During the subsequent heating step, the aldehydes tended to decrease, and we attribute this to their volatile nature, suggesting that they are lost by volatilization quicker than they are formed. However, this was not the case for 2-heptanone and 2-nonanone, which demonstrated a consistent increase with each additional processing stage and a significant increase after heat treatment. The longer chain ketones (2-decanone and 2-undecanone) and 2-pentylfuran were almost exclusively formed during the heating step. The trends were consistent across the samples regardless of the concentration method.

Free fatty acids (FFA) have been identified as major contributors to the flavor of milk fat by Schieberle et al. (1993) and were detected in all RWM samples. They have also been reported in SMP (Karagül-Yüceer et al., 2001), although our results show that most were removed when the milk was first pasteurized and skimmed, consistent with Drake et al. (2006). Concentration by $\mathrm{RO}$ led to an increase in FFA concentration that continued with heat treatment, although levels were much lower than those observed in the starting RWM. Without a double bond, saturated FFA are less reactive than unsaturated FFA and as a result are likely to be more heat-stable at lower heating temperatures, such as those applied during the concentration step. As part of the pasteurization step, the milk was skimmed by centrifugation immediately followed by pasteurization. It is possible that the large decrease in FFA concentration between RWM and PM could be due to the separation process and the removal of FFA with the milk fat. This would result in an initial decrease in concentration followed by an increase as they are formed via lipid oxidation during further processing.

The effect of thermal processing is most apparent for volatile compounds formed as a result of thermal degradation and the Maillard reaction. Sulfur compounds and Maillard reaction products (MRP) were detected only in heat-treated samples and generally in larger amounts for samples concentrated by RO, although the differences between $\mathrm{RO}$ and $\mathrm{EV}$ were not significant in most cases.

Maillard Reaction Products. The first stage of the Maillard reaction in milk involves the reaction of lactose with lysine $\varepsilon$-amino groups in proteins to form the ARP lactulosyllysine. This ARP can break down via different pathways to give large numbers of volatile flavor compounds. At low $\mathrm{pH}$, dehydration of the ARP leads to the formation of 2 -furfural. The presence of 2 -furfural in both HCM samples confirms that the Maillard reaction is taking place to a greater degree under the most severe processing conditions $\left(5 \mathrm{~min}\right.$ at $\left.125^{\circ} \mathrm{C}\right)$. Two furan derivatives, 2-furfural and 2-furanmethanol, were previously identified in SMP by Shiratsuchi et al. (1994) but were not thought to contribute to the flavor 


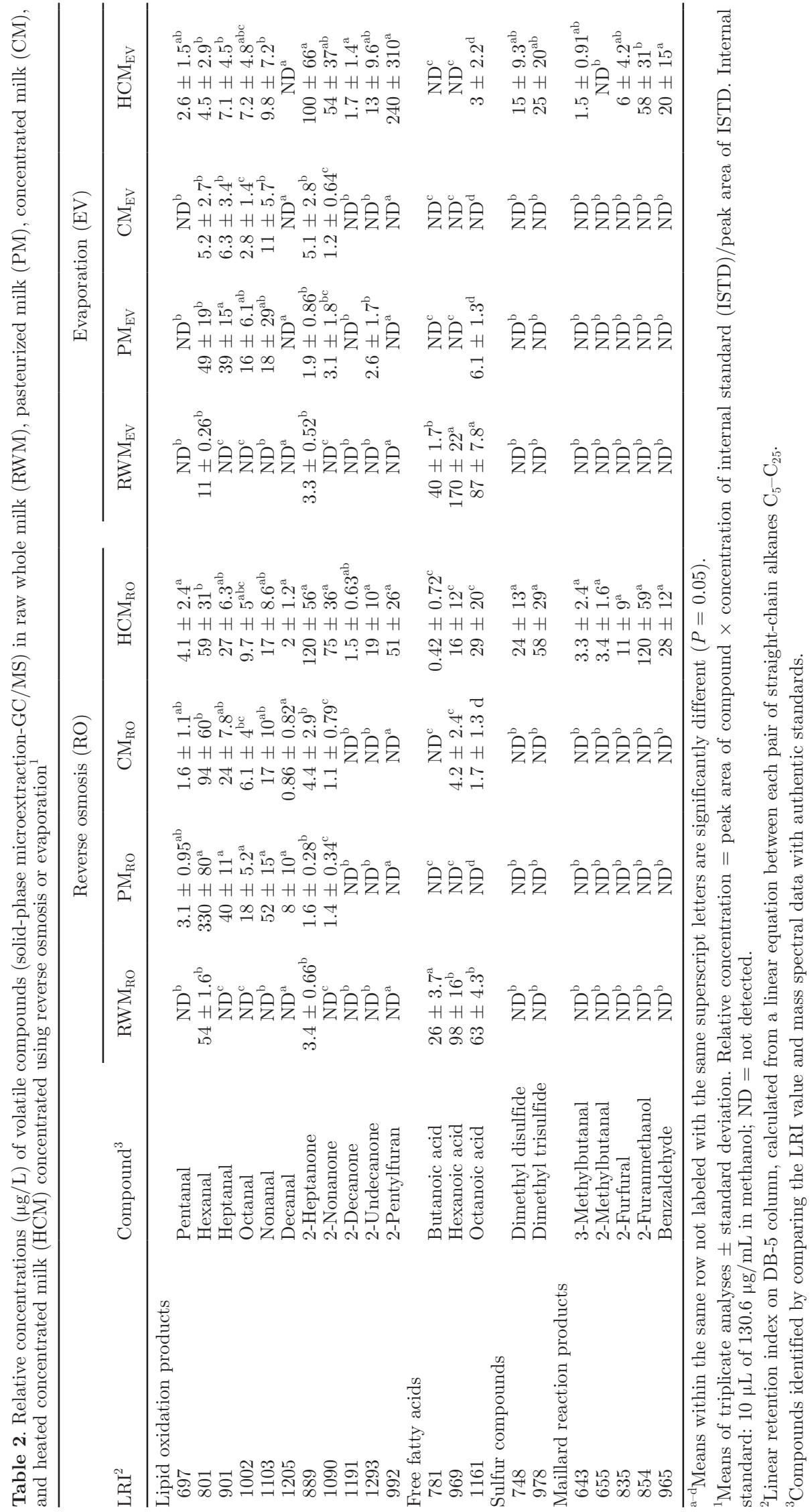


CHANGES IN FLAVOR PROFILE OF SKIM MILK POWDER

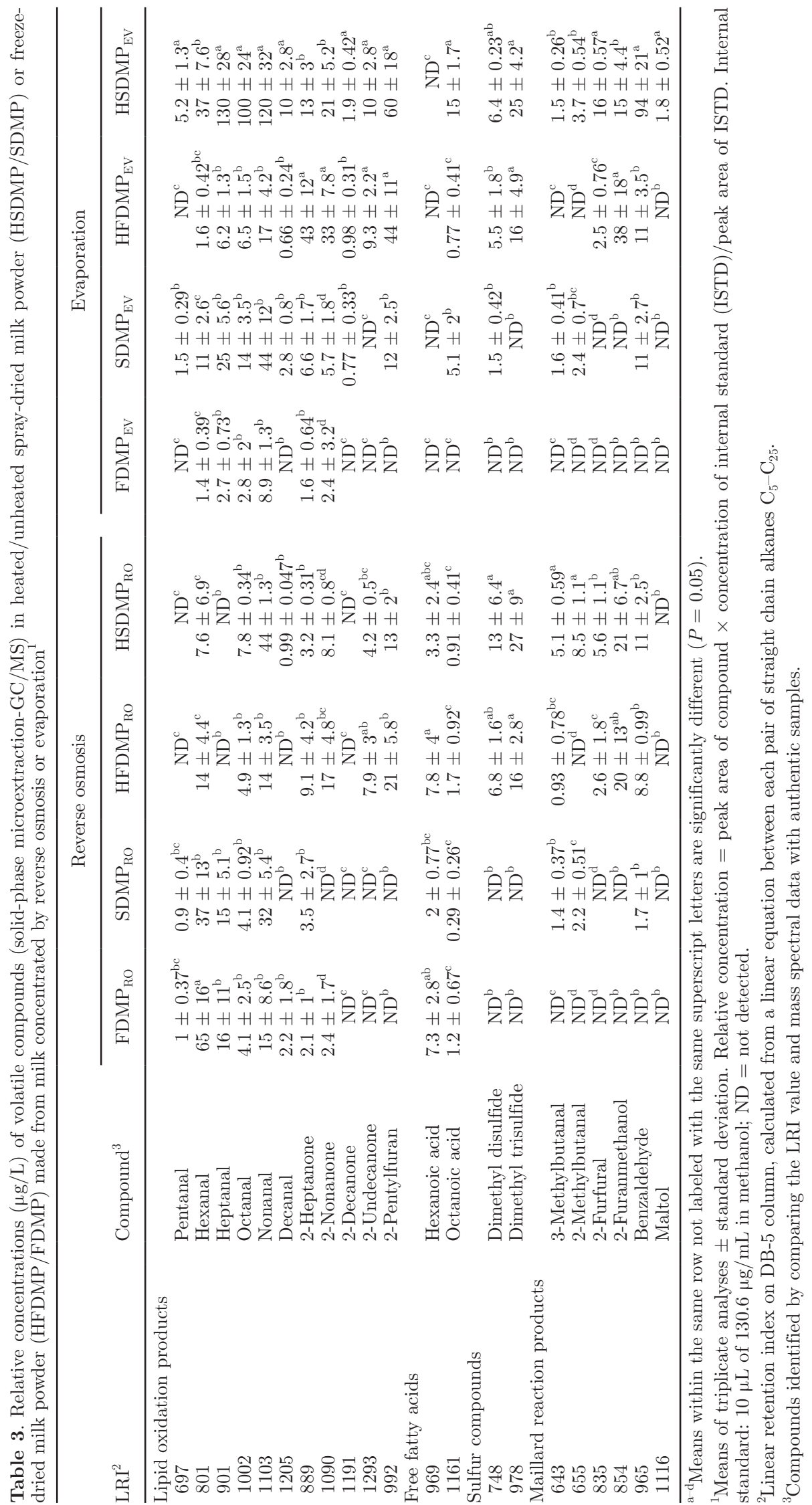


of milk due to their low concentrations and high odor thresholds (2 and $3 \mathrm{mg} / \mathrm{kg}$, respectively; Buttery and Ling, 1995).

In summary, MRP were only detected in samples that had undergone the heat treatment step and no clear differences were observed between flavor formation in samples concentrated by RO or EV.

Considering that the EV batch had a slightly higher concentration of Maillard precursors (Table 1) and the EV process involved higher temperatures than the RO process $\left(\mathrm{RO}=35^{\circ} \mathrm{C}, \mathrm{EV}=55^{\circ} \mathrm{C}\right)$, it is interesting to find that 2 significant differences were only present in $\mathrm{MRP}$ when comparing $\mathrm{HCM}_{\mathrm{EV}}$ and $\mathrm{HCM}_{\mathrm{RO}}$, and the general trend was for fewer MRP in $\mathrm{HCM}_{\mathrm{EV}}$. Therefore it seems likely that the difference in temperature between the 2 methods was not sufficient to cause significant differences in flavor compounds formed from the Maillard reaction.

Dimethyl disulfide and dimethyl trisulfide were previously identified as key contributors to the heated flavor of UHT milk by Al-Attabi et al. (2009) and can be formed by the Strecker degradation of methionine during thermal processing. Similarly, 3-methylbutanal and 2-methylbutanal are Strecker aldehydes formed from leucine (Ramshaw and Dunstone, 1969) and isoleucine (Griffith and Hammond, 1989), respectively. Both have previously been identified in raw, pasteurized, and UHT milk (Vazquez-Landaverde et al., 2005) as well as in milk powder (Hall et al., 1985; Lloyd et al., 2009a,b).

\section{Volatile Compounds in Skim Milk Powders}

Table 3 shows the volatile compounds identified in reconstituted milk powders, and comparison with samples from the early processing stages reveals that the majority of compounds appear in both sample sets and aldehydes and ketones remain the most abundant group of compounds.

Lipid-Derived Volatiles. The first thing to observe is that the low solids content before spray-drying $(20 \%$ compared with $40-50 \%$ typically used in industry) may have promoted lipid oxidation as discussed by Park at al. (2016). We observed a significant difference in the concentration of lipid-derived aldehydes in EV powders, with spray-dried powders consistently having a higher concentration than freeze-dried; thus, the highest concentration of lipid-derived aldehydes was found in $\mathrm{HSDMP}_{\mathrm{EV}}$. This supports previous work by Li et al. (2012), which concluded that heat treatment of milk before concentration and spray-drying results in accelerated formation of aldehydes and ketones. A similar trend was not observed for all RO powders or for other lipid oxidation products, such as methylketones.
Comparison of $\mathrm{HSDMP}_{\mathrm{EV}}$ and $\mathrm{HSDMP}_{\mathrm{RO}}$ revealed that 11 of the lipid-derived compounds were higher in the powders prepared by EV. This is unlikely to be related to differences between the batches of milk because the profiles of the lipid-derived volatiles before concentration were very similar (apart from hexanal, which was higher in RO). We suggest that the milk is more prone to lipid oxidation during the EV stage, where it is exposed to light and oxygen as well as mild thermal conditions. Once initiated, the oxidation continues during heating and spray-drying. We suggest that RO is likely to be a more effective concentration method to limit the formation of lipid oxidation products during manufacture of SMP, particularly if it is heated and spray-dried.

Hexanoic acid was only detected in RO samples and although there was no difference between heat treatments, the freeze-dried samples had significantly higher concentrations than their spray-dried equivalents. Conversely, octanoic acid was detected in both $\mathrm{EV}$ and $\mathrm{RO}$ samples but only the EV samples showed significant differences, as a result of both drying method and heat treatment. Loss of VFA during conching was shown to take place by Hoskin and Dimick (1979) and spraydrying of milk powder could yield similar results. The temperature of milk particles during spray-drying (wet bulb temperature) was 45 to $50^{\circ} \mathrm{C}$ and in combination with the EV of water this could have led to the lower concentration of FFA in SDMP compared with FDMP produced from the same HCM.

Maillard Reaction Products. Significant differences were seen between powders for sulfur compounds and MRP, which were generally at higher concentrations or only present in heated samples, consistent with Drake et al. (2006). Dimethyl trisulfide is one of the compounds that is likely to contribute to the flavor profile of the heat-treated powders (Stewart et al., 2017). It was only detected in the heat-treated milks and in the powders produced from the heat-treated milks, and there was no difference between the products prepared by EV or RO. The less odor active dimethyl disulfide showed a similar trend.

Two Maillard-derived compounds, benzaldehyde and 3-hydroxy-2-methyl-4H-pyran-4-one (maltol), were significantly affected by the combination of concentration, heat treatment, and drying methods used. KaragülYüceer et al. (2001) previously identified maltol in SMP of various heat treatments, but a higher intensity was perceived in the high-heat-treated powder. Maltol is derived from the Maillard reaction of disaccharides such as lactose at high temperatures (Patton, 1950; Yaylayan and Mandeville, 1994) and was only detected after the most severe processing $\left(\mathrm{HSDMP}_{\mathrm{EV}}\right)$. It is one 
of the compounds reported by Stewart et al. (2017) that are likely to contribute to the more caramel-like flavor in the heat-treated powders.

The amount of benzaldehyde detected correlated with the level of thermal processing applied and its concentration was in the following order: HSDMP > HFDMP $>$ SDMP, with none detected in FDMP. Benzaldehyde can be formed from the thermal reaction of lactose with phenylalanine (Ramshaw and Dunstone, 1969), and has been identified previously in stored milk powder (Parks and Patton, 1961). Benzaldehyde was detected in a significantly larger amount in HSDMP concentrated by EV: over 8 times that of the next highest concentration. However, based on the results of Stewart et al. (2017), it is unlikely to contribute to the flavor of the SMP.

\section{Model White Chocolate}

To evaluate the effect of different milk powder processing conditions after incorporation into a confectionery product, a series of model white chocolate samples was produced under different conching conditions. For this study, each milk powder was used to produce one batch of model white chocolate conched under normal conditions $\left(4 \mathrm{~h}\right.$ at $\left.50^{\circ} \mathrm{C}\right)$ and one batch produced under more extreme heating conditions $\left(8 \mathrm{~h}\right.$ at $\left.80^{\circ} \mathrm{C}\right)$. Twenty-five volatile compounds were monitored by SPME GC-MS. The volatile profile of the products conched at $80^{\circ} \mathrm{C}$ are shown in Table 4 , but those conched at $50^{\circ} \mathrm{C}$ showed very few significant differences between the samples and the full data are not shown. Apart from the short-chain acids that tended to show no significant difference across the 8 products, the volatiles fall into 2 groups according to their overall trends across the $80^{\circ} \mathrm{C}$ samples.

Lipid-Derived Volatiles. The lipid degradation products all followed a pattern similar to that shown for 2-heptanone (Figure 4). This included 2-pentanone and 2-nonanone as well as hexanal, heptanal, octanal, and nonanal. Although we cannot account for differences in flavor release, the fact that no significant difference was present across the set of samples conched at $50^{\circ} \mathrm{C}$ suggests that the differences observed at $80^{\circ} \mathrm{C}$ are not just a result of different flavor release properties of the samples. The increase in these lipid-derived compounds at $80^{\circ} \mathrm{C}$ is consistent with Counet et al. (2002) who showed an increase in 2-heptanone at high-temperature conching. The samples made with freeze-dried SMP showed an increase in lipid-derived compounds when compared with the spray-dried equivalents, and we attribute that to the increase in moisture content of the freeze-dried material. Within the products made with spray-dried SMP, no significant differences were observed where different milk processing conditions had been used, consistent with the data from the SMP.

Maillard Reaction Products. This comprises a group of Maillard sugar breakdown products: 2-furfural, 2-furanmethanol, methyl 2-furoate, and maltol, but interestingly not the pyrazines and Strecker aldehydes, which generally require high-temperature processing for their formation. These sugar degradation products all follow the trend shown in Figure 4 for maltol. Again we see the highest concentrations present in those samples containing freeze-dried SMP, and attribute this to the increase in moisture. Franzen et al. (1990) found $7 \%$ to be the optimum moisture content for the Maillard reaction in SMP. The milk powders produced in this study had moisture contents in the range of 2.7 to $6.1 \%\left(\mathrm{a}_{\mathrm{w}} 0.15-0.25\right)$, which is below the optimum, and once incorporated into the fat phase of the white chocolate the overall moisture content would be lower again. Thus the slightly higher moisture content of the freeze-dried SMP (Figure 2) moves the system closer to the browning-critical moisture content, thus promoting the formation of these Maillard-derived compounds.

However, we also observed that those samples containing freeze-dried SMP, where the milk had been concentrated by EV rather than RO, contained 10 to 20 times more maltol and other sugar degradation products. We suggest that this can only be due to the formation of precursors as a result of the mild heat treatment applied during the EV stage. This is supported by the loss of sugars and free amino groups at this stage, with there being a significant loss of free amino groups in the EV concentrated milk but not the RO concentrated milk (Table 1). However, we observe the effect of the heat treatment applied to the milk in the set of products made from spray-dried SMP. The concentration of maltol is significantly higher when the additional heat treatment was applied, and 2-furfural, 2-furanmethanol, acetic acid, and hydroxypropanone all followed a similar trend. This is consistent with the differences found in the constituent SMP (Table 3).

\section{CONCLUSIONS}

Overall, this work highlights the importance of the combinations and interactions of the model processes chosen for each stage of SMP and confectionery manufacture, on the development of volatile aroma compounds in model white chocolate. Use of EV as a drying method seemed to initiate lipid oxidation, which resulted in significantly higher lipid-derived volatiles in the milk powder when further heat treatment was applied. For production of Maillard-derived compounds in SMP, heat treatment was the most important process- 


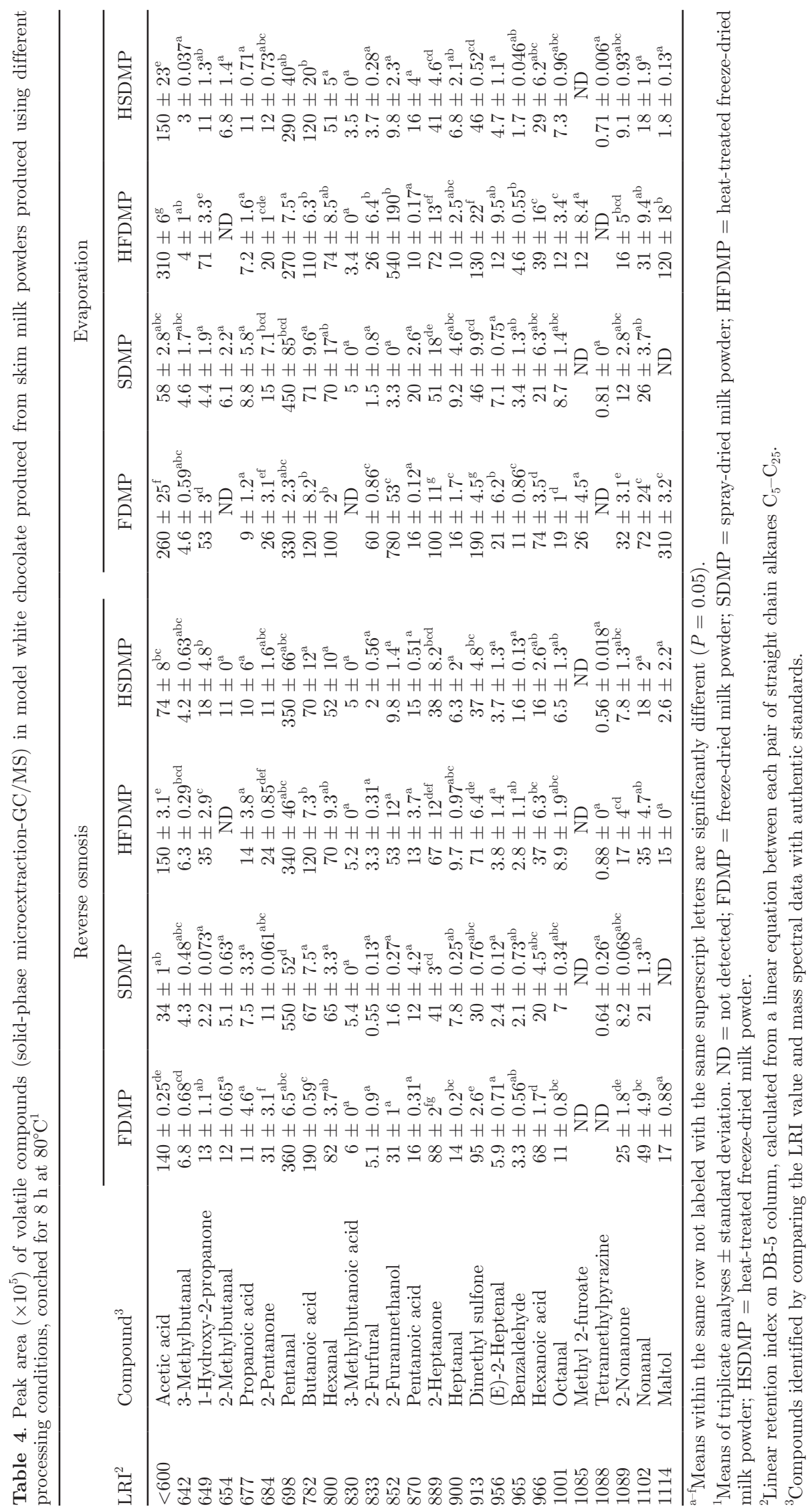



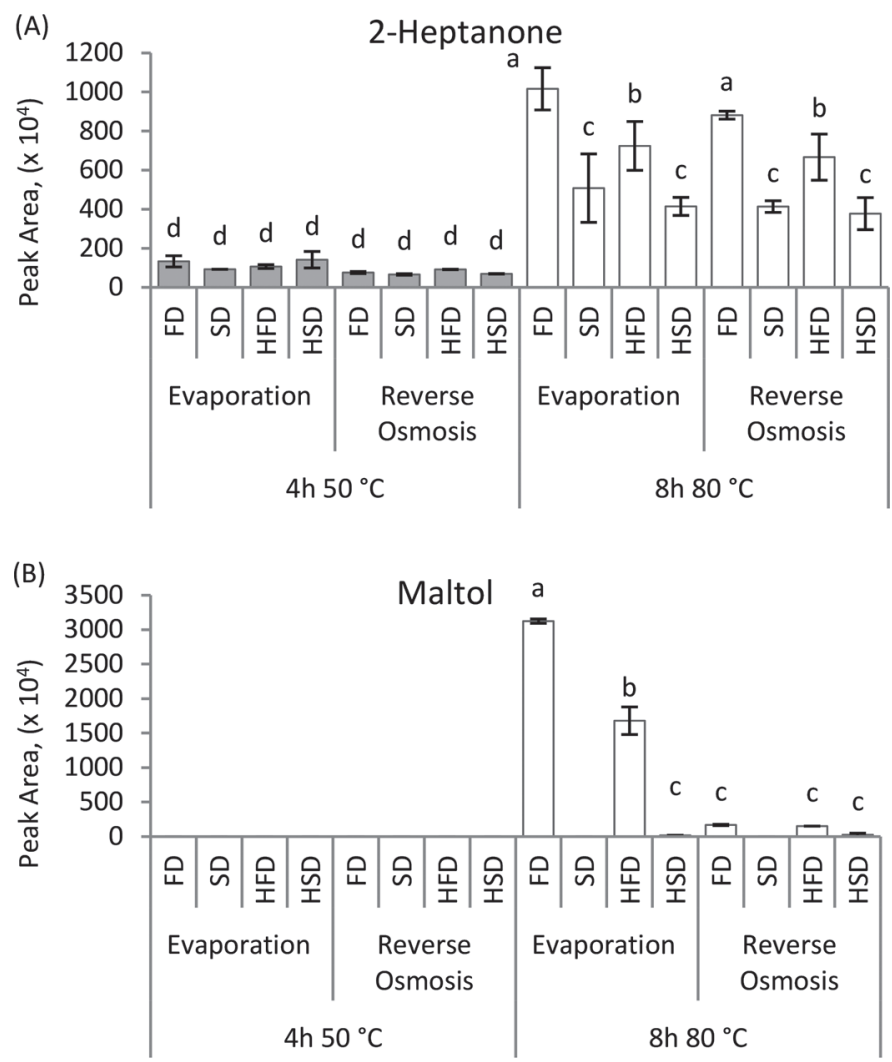

Figure 4. Comparative analysis (solid-phase microextraction-GC/ MS) of (A) 2-heptanone, and (B) maltol in model white chocolate containing skim milk powder produced with different combinations of processing conditions: concentration by reverse osmosis or evaporation, low or high heat treatment ( $\mathrm{H}=$ high heat treatment), and drying by either freeze-drying (FD) or spray-drying (SD). Mean of triplicate analyses shown \pm standard deviation as error bars. Bars not labeled with the same letters are significantly different $(P<0.05)$.

ing stage and was the first stage at which MRP were identified. The application of further heat during spraydrying led to increased levels of MRP compared with freeze-dried samples. The concentration method seemed to have very little influence on the Maillard reaction, except that maltol, an important aroma compound, was only found in the high-heat, spray-dried powder that had been concentrated using EV. The volatile profile of the white chocolate was shown to be driven by several factors that include moisture content of the SMP, method of concentration, and application of heat. The interrelation of these mechanism is complex, but here we show that changes in these unit operations can quite significantly alter the volatile profile, in particular the combination of concentration by EV when the moisture content of the SMP is somewhat higher than is typically used within the industry. In general, we have shown that these stages of processing are interdependent, and early stages of SMP manufacture can have an effect on the volatile profile of model white chocolate.
The results of this investigation are potentially useful for the dairy and confectionery industries in controlling the volatile profile of their final product.

\section{ACKNOWLEDGMENTS}

This research was funded by the Biotechnology and Biological Sciences Research Council (Swindon, UK; BB/J500860/1) and Nestlé Product Technology Centre York (United Kingdom) through a Collaborative Award in Science and Engineering studentship.

\section{REFERENCES}

Al-Attabi, Z., B. D'arcy, and H. Deeth. 2009. Volatile sulphur compounds in UHT milk. Crit. Rev. Food Sci. Nutr. 49:28-47.

Bassette, R., and M. Keeney. 1960. Identification of some volatile carbonyl compounds from nonfat dry milk. J. Dairy Sci. 43:17441750 .

Berg, H. E., and M. A. J. S. Van Boekel. 1994. Degradation of lactose during heating of milk. 1. Reaction pathways. Netherlands Milk Dairy J. 48:157-175.

Birlouez-Aragon, I., M. Pischetsrieder, J. Leclere, F. Morales, K. Hasenkopf, R. Kientsch-Engel, C. Ducauze, and D. Rutledge. 2004. Assessment of protein glycation markers in infant formulas. Food Chem. 87:253-259.

Brands, C. M. J., and M. A. J. S. Van Boekel. 2001. Reactions of monosaccharides during heating of sugar-casein systems: Building of a reaction network model. J. Agric. Food Chem. 49:4667-4675.

Buttery, R. G., and L. C. Ling. 1995. Volatile flavor components of corn tortillas and related products. J. Agric. Food Chem. 43:18781882.

Cattaneo, S., F. Masotti, and L. Pellegrino. 2008. Effects of overprocessing on heat damage of UHT milk. Eur. Food Res. Technol. 226:1099-1106.

Caudle, A. D., Y. Yoon, and M. Drake. 2005. Influence of flavor variability in skim milk powder on consumer acceptability of ingredient applications. J. Food Sci. 70:s427-s431.

Celestino, E. L., M. Iyer, and H. Roginski. 1997. Reconstituted UHTtreated milk: Effects of raw milk, powder quality and storage conditions of UHT milk on its physico-chemical attributes and flavour. Int. Dairy J. 7:129-140.

Contarini, G., M. Povolo, R. Leardi, and P. M. Toppino. 1997. Influence of heat treatment on the volatile compounds of milk. J. Agric. Food Chem. 45:3171-3177.

Counet, C., D. Callemien, C. Ouwerx, and S. Collin. 2002. Use of gas chromatography-olfactometry to identify key odorant compounds in dark chocolate. Comparison of samples before and after conching. J. Agric. Food Chem. 50:2385-2391.

Drake, M. A., R. E. Miracle, A. D. Caudle, and K. R. Cadwallader. 2006. Relating sensory and instrumental analysis. Pages $23-55$ in Sensory-Directed Flavor Analysis. R. Marsili, ed. Taylor and Francis, Boca Raton, FL.

Driscoll, N., C. Brennand, and D. Hendricks. 1985. Sensory quality of nonfat dry milk after long-term storage. J. Dairy Sci. 68:19311935.

Early, R. 1998. Technology of Dairy Products. Springer, New York, NY.

Elmore, J. S., D. S. Mottram, N. Muttucumaru, A. T. Dodson, M. A. Parry, and N. G. Halford. 2007. Changes in free amino acids and sugars in potatoes due to sulfate fertilization and the effect on acrylamide formation. J. Agric. Food Chem. 55:5363-5366.

Erbersdobler, H. F., and V. Somoza. 2007. Forty years of furosineForty years of using Maillard reaction products as indicators of the nutritional quality of foods. Mol. Nutr. Food Res. 51:423-430.

Franzen, K., R. K. Singh, and M. R. Okos. 1990. Kinetics of nonenzymatic browning in dried skim milk. J. Food Eng. 11:225-239. 
Glover, F. 1985. Ultrafiltration and reverse osmosis for the dairy industry. Technical Bulletin 5. National Institute for Research in Dairying, Reading, UK.

Griffith, R., and E. G. Hammond. 1989. Generation of Swiss cheese flavor components by the reaction of amino acids with carbonyl compounds. J. Dairy Sci. 72:604-613.

Hall, G., J. Andersson, H. Lingnert, and B. Olofsson. 1985. Flavor changes in whole milk powder during storage. J. Food Qual. 7:153190.

Hoskin, J., and P. Dimick. 1979. Volatile fatty acid changes during the conching of chocolate. Pages 23-32 in Proc. 33rd PMCA Production Conference.

Hurrell, R. F., P. A. Finot, and J. E. Ford. 1983. Storage of milk powders under adverse conditions. 1. Losses of lysine and of other essential amino acids as determined by chemical and microbiological methods. Br. J. Nutr. 49:343-354.

Karaguel-Yueceer, Y., M. A. Drake, and K. R. Cadwallader. 2003 Aroma characterization of fresh and stored nonfat dry milk. in Freshness and shelf life of foods. Vol. 836. K. R. Cadwallader and H. Weenen, ed. ACS Symposium Series, Washington, DC.

Karagül-Yüceer, Y., K. R. Cadwallader, and M. Drake. 2002. Volatile flavor components of stored nonfat dry milk. J. Agric. Food Chem. 50:305-312.

Karagül-Yüceer, Y., M. Drake, and K. R. Cadwallader. 2001. Aroma-active components of nonfat dry milk. J. Agric. Food Chem. 49:2948-2953

Li, Y., L. Zhang, and W. Wang. 2012. Formation of aldehyde and ketone compounds during production and storage of milk powder. Molecules 17:9900-9911.

Lloyd, M. A., M. A. Drake, and P. D. Gerard. 2009a. Flavor variability and flavor stability of U.S.-produced whole milk powder. J. Food Sci. 74:S334-S343.

Lloyd, M. A., J. S. Hess, and M. A. Drake. 2009b. Effect of nitrogen flushing and storage temperature on flavor and shelf-life of whole milk powder. J. Dairy Sci. 92:2409-2422.

Marconi, E., M. C. Messia, A. Amine, D. Moscone, F. Vernazza, F. Stocchi, and G. Palleschi. 2004. Heat-treated milk differentiation by a sensitive lactulose assay. Food Chem. 84:447-450.

Martin, G., R. Williams, and D. Dunstan. 2007. Comparison of casein micelles in raw and reconstituted skim milk. J. Dairy Sci. 90:4543-4551.

Mehta, B. M., and H. C. Deeth. 2016. Blocked lysine in dairy products: Formation, occurrence, analysis, and nutritional implications. Compr. Rev. Food Sci. Food Saf. 15:206-218.

Miao, S., and Y. Roos. 2004. Comparison of nonenzymatic browning kinetics in spray-dried and freeze-dried carbohydrate-based food model systems. J. Food Sci. 69:322-331.

Morales, F. J., C. Romero, and S. Jimenez-Perez. 1992. An enhanced liquid chromatographic method for 5-hydroxymethylfurfural determination in UHT milk. Chromatographia 33:45-48.

O'Brien, J. 2003. Non-Enzymatic Degradation Pathways of Lactose and Their Significance in Dairy Products. in Advanced Dairy Chemistry, Volume 3: Lactose, Water, Salts and Minor Constituents. 3rd ed. P. Fox and P. McSweeney, ed. Kluwer Academic/ Plenum, Amsterdam, the Netherlands.

Oldfield, D., M. Taylor, and H. Singh. 2005. Effect of preheating and other process parameters on whey protein reactions during skim milk powder manufacture. Int. Dairy J. 15:501-511.
Park, C. W., and M. Drake. 2016. Condensed milk storage and evaporation affect the flavor of nonfat dry milk. J. Dairy Sci. 99:95869597

Park, C. W., M. A. Stout, and M. A. Drake. 2016. The effect of spraydrying parameters on the flavor of nonfat dry milk and milk protein concentrate 70\%. J. Dairy Sci. 99:9598-9610.

Parks, O. W., and S. Patton. 1961. Volatile carbonyl compounds in stored dry whole milk. J. Dairy Sci. 44:1-9.

Patton, S. 1950. The isolation of maltol from heated skim milk. J. Dairy Sci. 33:102-106.

Ramshaw, E., and E. Dunstone. 1969. Volatile compounds associated with the off-flavour in stored casein. J. Dairy Res. 36:215-223.

Romero, C., F. J. Morales, and S. Jiménez-Pérez. 2001. Effect of storage temperature on galactose formation in UHT milk. Food Res. Int. 34:389-392.

Schieberle, P., K. Gassenmeier, H. Guth, A. Sen, and W. Grosch. 1993 Character impact odour compounds of different kinds of butter. Lebensm. Wiss. Technol. 26:347-356.

Shimamura, T., and H. Ukeda. 2012. Maillard reaction in milk-Effect of heat treatment. Pages 147-158 in Milk Protein. W. L. Hurley, ed. InTechOpen Science, London, UK.

Shiratsuchi, H., M. Shimoda, K. Imayoshi, K. Noda, and Y. Osajima. 1994. Volatile flavor compounds in spray-dried skim milk powder. J. Agric. Food Chem. 42:984-988.

Smit, G. 2003. Dairy Processing: Improving Quality. Woodhead Publishing, Cambridge, UK.

Stewart, A., A. S. Grandison, A. Ryan, D. Festring, L. Methven, and J. K. Parker. 2017. The impact of the skim milk powder manufacturing process on the flavor of model white chocolate. J. Agric. Food Chem. 65:1186-1195.

Stewart, A., A. S. Grandison, A. Ryan, and J. K. Parker. 2015. Investigating the Maillard reaction of milk powder in a low-moisture system. Pages 245-248 in Proceedings of XIV Weurman Flavour Research Symposium. A. D. Taylor and D. S. Mottram, ed. Context Products Ltd., Packington, Cambridge, UK.

Syrios, A., M. Faka, A. S. Grandison, and M. J. Lewis. 2011. A comparison of reverse osmosis, nanofiltration and ultrafiltration as concentration processes for skim milk prior to drying. Int. J. Dairy Technol. 64:467-472.

Tokuşoğlu, O., A. S. Akalin, and M. K. Unal. 2004. A rapid high performance liquid chromatographic detection of furosine (.vepsiln.N-2-furoylmethyl-L-lysine) in pasteurized and UHT milks. Milchwissenschaft 59:502-505.

Valero, E., M. Villamiel, B. Miralles, J. Sanz, and I. Martínez-Castro. 2001. Changes in flavour and volatile components during storage of whole and skimmed UHT milk. Food Chem. 72:51-58.

Van Boekel, M. A. J. S. 1998. Effect of heating on Maillard reactions in milk. Food Chem. 62:403-414.

Vazquez-Landaverde, P. A., G. Velazquez, J. A. Torres, and M. C. Qian. 2005. Quantitative determination of thermally derived offflavor compounds in milk using solid-phase microextraction and gas chromatography. J. Dairy Sci. 88:3764-3772.

Walker, N. J. 1972. Flavour defects in edible casein and skim-milk powder: I. The role of Maillard browning. J. Dairy Res. 39:231-238.

Yaylayan, V. A., and S. Mandeville. 1994. Stereochemical control of maltol formation in Maillard reaction. J. Agric. Food Chem. 42:771-775. 